\title{
Analisa Stakeholder dalam Program Konsolidasi Tanah di Desa Gadingsari Kecamatan Sanden Kabupaten Bantul
}

\author{
Nuryusriana $^{1^{*}}$ dan Ahmad Sarwadi ${ }^{2}$
}

1 Magister Perencanaan Wilayah dan Kota Universitas Gadjah Mada, Jl. Grafika No.2, Yogyakarta

2 Magister Perencanaan Wilayah dan Kota Universitas Gadjah Mada, Jl. Grafika No.2, Yogyakarta

* Korespondensi: email: Desmont27@yahoo.com

\begin{tabular}{ll} 
ARTICLE INFO & ABSTRACT \\
\hline Keywords: & Gadingsari village land consolidation program is a land consolidation in \\
stakeholders & residential areas that has been implemented from 2009 to 2018, except in 2012, \\
& 2014, and 2016, with 2.034 arranged plots and with total area of 1.168.793 m2. \\
& Land consolidation is implemented on a single land expanse and continued by \\
& the contiguous expanse to generate a physically and administratively organized \\
Received: October 29, 2021 & area. This study aimed to identify and analyze stakeholders in Gadingsari land \\
Reviewed: October 30, 2021 & consolidation program. This study used a qualitative descriptive method. The \\
Accepted: November 5, 2021 & results showed that there are 13 stakeholders involved in the land consolidation \\
& program and can be mapped into four quadrants: (1) subject consisting of \\
& community work program (pokmas); (2) key players consisting of Ministry \\
& ATR/BPN of the Republic of Indonesia ATR/BPN Yogyakarta Special Region \\
& Province, ATR/BPN Bantul Regency, land-owning communities, and Gadingsari \\
& village government; (3) supporters consisting of the Regent of Bantul, Bappeda \\
of Bantul Regency, Bantul Regency Spatial Planning Office, Bantul Regency & Public Work Office, Bantul Regency Agriculture Office, Sanden District \\
& Government; and (4) public figures. This study also found six typology roles of \\
& stakeholders such as policy creator, planner, coordinator, facilitator, \\
implementer, and mediator.
\end{tabular}

INFO ARTIKEL

Kata Kunci:

Konsolidasi tanah, peran,

stakeholder

\section{How To Cite :}

Nuryusriana., Sarwadi. A. (2021). Analisa Stakeholder dalam Program Konsolidasi Tanah di Desa Gadingsari Kecamatan Sanden Kabupaten Bantul. Marcapada: Jurnal Kebijakan Pertanahan, 1(1), 90-104

\section{ABSTRAK}

Pelaksanaan program konsolidasi tanah desa Gadingsari merupakan konsolidasi tanah di area permukiman yang telah dilaksanakan mulai tahun 2009 sampai dengan 2018, kecuali tahun 2012, 2014 dan 2016, dengan 2.034 bidang tertata dan jumlah luas $1.168 .793 \mathrm{~m} 2$. Konsolidasi tanah dilaksanakan pada satu hamparan dan dilanjutkan dengan hamparan di sebelahnya untuk menghasilkan wilayah yang tertata baik secara fisik dan secara administrasi pertanahannya. Penelitian ini bertujuan untuk mengidentifikasi dan menganalisis stakeholder pada program konsolidasi tanah di Desa Gadingsari. Penelitian ini menggunakan metode deskriptif kualitatif. Temuan penelitian ini menunjukkan adanya 13 stakeholder dalam program konsolidasi tanah dan dapat dipetakan menjadi empat kuadran: (1) subjek yang terdiri atas pokmas; (2) pemain kunci yang terdiri atas: Kementerian ATR/ BPN Republik Indonesia; ATR/BPN Provinsi Daerah Istimewa Yogyakarta; ATR/BPN Kabupaten Bantul; masyarakat pemilik tanah; dan pemerintah desa Gadingsari; (3) pendukung yang terdiri atas Bupati Bantul, Bappeda Kabupaten Bantul; Dinas Tata Ruang Kabupaten Bantul; Dinas Pekerjaan Umum Kabupaten Bantul; Dinas Pertanian Kabupaten Bantul; Pemerintah Kecamatan Sanden; dan (4) tokoh masyarakat. Penelitian ini juga menunjukkan peran stakeholder dalam program konsolidasi tanah antara lain pembuat kebijakan, perencana, koordinator, fasilitator, pelaksana, dan mediator. 


\section{A. Pendahuluan}

Ketersediaan lahan yang terbatas dan jumlah penduduk yang semakin meningkat merupakan suatu permasalahan utama yang dihadapi dalam era pembangunan saat ini. Adanya keterbatasan lahan yang tidak diimbangi dengan laju pertumbuhan penduduk menimbulkan beberapa permasalahan dalam penataan ruang, diantaranya ketidakteraturan dalam penggunaan ruang, timbulnya permukiman kumuh, belum tersedianya fasilitas umum dan menurunnya kualitas lingkungan. Permasalahan-permasalahan tersebut menunjukkan bahwa diperlukan sistem pengaturan pertanahan yang mampu mengatur penggunaan, pemanfaatan, dan kepemilikan tanah sehingga dapat terwujud kesejahteraan bagi masyarakat.

Menurut (Prabowo, 2015) di Indonesia masih terdapat bidang-bidang tanah yang belum mempunyai akses menuju bidang tanah yang dimaksud. Aksesibilitas merupakan suatu hal yang sangat penting bagi suatu lahan. Secara ekonomis aksesibilitas lahan juga mampu meningkatkan harga lahan. Sebagai langkah dalam mengatasi konflik-konflik yang berhubungan dengan lahan seperti telah dijelaskan diatas, maka diperlukan pengaturan mengenai penguasaan dan pemanfaatan lahan secara optimal. Program konsolidasi tanah dapat dijadikan alternatif solusi dalam upaya mewujudkan fungsi sosial tanah serta usaha meningkatkan kualitas lingkungan. Program konsolidasi tanah di Desa Gadingsari Kabupaten Bantul dilakukan dengan berbasis pada community development (pembangunan komunitas) yang berupa kelompok kerja dalam masyarakat. Pada pelaksanaannya, terdapat kelompok masyarakat (pokmas) yang dibentuk untuk melaksanakan program konsolidasi tanah. Konsolidasi tanah Desa Gadingsari merupakan program lintas sektor yang melibatkan beberapa stakeholder dalam pelaksanaannya baik dari pemerintah maupun masyarakat.

Peraturan Menteri Agraria dan Tata Ruang/Kepala Badan Pertanahan Nasional Nomor 12 Tahun 2019 menyebutkan bahwa konsolidasi tanah merupakan kebijakan pertanahan mengenai penataan kembali penguasaan, pemilikan, penggunaan dan pemanfaatan tanah dan ruang sesuai rencana tata ruang serta usaha penyediaan tanah untuk kepentingan umum dan pemberi jaminan kepastian hukum hak atas tanah yang bertujuan meningkatkan kualitas lingkungan hidup dan pemeliharaan sumber daya alam, dengan melibatkan partisipasi aktif. Jayadinata (1999) menyebutkan bahwa program konsolidasi tanah merupakan model pembangunan di bidang pertanahan pada wilayah perkotaan dan perdesaan dengan tujuan mengoptimalkan penggunaan dan pemanfaatan tanah, peningkatan produktivitas lahan dan konservasi lingkungan. Prinsip pada program konsolidasi tanah merupakan penataan bidang-bidang tanah yang tidak beraturan menjadi bidang tanah yang teratur dan memiliki aksesibilitas yang baik. Pelaksanaannya dilakukan dengan langkah menggeser, menggabung, memecah, menghapus dan mengubah hak atas tanah serta penataan sarana dan prasarana kepentingan umum yang diperlukan masyarakat. Penataan yang dilakukan pada program konsolidasi tanah disesuaikan dengan RTRW daerah setempat. Menurut pernyataan Sitorus (1996) bahwa tujuan pelaksanaan konsolidasi tanah adalah mewujudkan lingkungan yang berkualitas, dan merupakan kegiatan pengadaan tanah yang bertujuan untuk pembangunan dan pemeliharaan sumber daya dengan mengandalkan peran aktif masyarakat. 
Keberhasilan program konsolidasi tanah di Desa Gadingsari tidak terlepas dari peran stakeholder. Menurut Freeman (1984) stakeholder merupakan setiap kelompok ataupun individu yang berpengaruh dan juga dipengaruhi oleh masa depan suatu organisasi. Soesilo (2000) menyatakan bahwa hal yang paling penting adalah menentukan siapa (who) stakeholder utama dalam suatu program. Menentukan siapa stakeholder kunci memerlukan suatu perhatian khusus mengingat terdapat banyak stakeholder yang terlibat dalam suatu program. Cohen \& Uphoff (1977) menyatakan pihak-pihak yang berperan serta dalam pembangunan terdiri atas unsur penduduk lokal, pemerintah lokal baik kota maupun kabupaten, pemerintah lokal provinsi dan pemerintah yang berada setingkat diatasnya (pusat).

Pelaksanaan program konsolidasi tanah di desa Gadingsari, stakeholder terdiri atas masyarakat dan pemerintah. Dalam menganalisis stakeholder tahap pertama yang harus dilakukan adalah menentukan pengaruh dan kepentingan (Reed et al., 2009) dalam (Wakka, 2014). Gambar 1 menunjukkan bahwa stakeholder dapat dikategorikan menjadi: (1) Stakeholder subyek yaitu stakeholder yang mempunyai kepentingan tinggi dalam suatu kegiatan/proyek tetapi mempunyai kapasitas yang rendah dalam mencapai tujuan kegiatan/proyek; (2) Stakeholder pemain kunci (key player) merupakan stakeholder yang memiliki pengaruh tinggi serta mempunyai kepentingan yang besar terhadap kegiatan/proyek; (3) Stakeholder pengikut lain (crowd) adalah stakeholder dimana tingkat kepentingan rendah serta mempunyai kekuatan yang kecil bagi kegiatan/proyek; (4) Stakeholder pendukung (contest setter) merupakan stakeholder yang mempunyai tingkat kepentingan rendah akan tetapi memiliki pengaruh yang tinggi terhadap kegiatan/proyek.

Gambar 1. Matrik Pengaruh dan Kepentingan

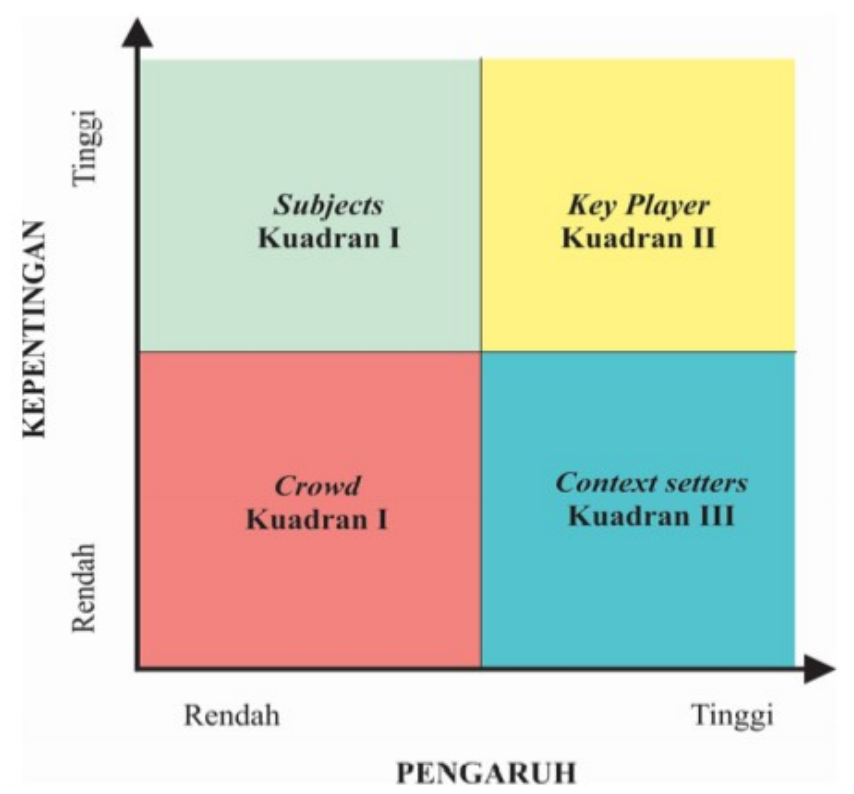

Sumber: Reed et All (Wakka, 2014)

Nugroho (2014) mengemukakan bahwa peran stakeholder dalam suatu kegiatan pembangunan yaitu: (1) Policy Creator yaitu peran stakeholder sebagai pengambil keputusan dan penentu suatu kebijakan; (2) Koordinator yaitu peran stakeholder mengkoordinasikan stakeholder lain yang terlibat; (3) Fasilitator yaitu peran stakeholder sebagai fasilitator yang berperan 
memfasilitasi dan mencukupi yang dibutuhkan kelompok sasaran; (4) Implementer yaitu peran stakeholder sebagai pelaksana kebijakan yang didalamnya merupakan kelompok sasaran; (5) Akselerator yaitu peran stakeholder mempercepat dan memberikan kontribusi agar program berjalan sesuai sasaran atau bahkan lebih cepat dari waktu yang sudah ditentukan.

Penelitian mengenai program konsolidasi tanah telah banyak dilakukan, diantaranya yaitu penelitian Imaduddin (2019) yang bertujuan untuk mengetahui konsep pelaksanaan konsolidasi tanah pada daerah bencana merapi di Desa Umbulharjo Kabupaten Sleman. Penelitian lain dilakukan Sinta (2019) yang bertujuan untuk mendeskripsikan secara runut tahapan penyelenggaraan konsolidasi tanah di Kabupaten Lima Puluh Kota dan mengidentifikasi faktorfaktor yang mempengaruhi belum tercapainya hasil konsolidasi tanah secara optimal di Kabupaten Lima Puluh Kota. Penelitian Suyanto (2013) bertujuan mengetahui faktor pendorong program konsolidasi tanah dan menemukan bahwa pemilik tanah, toko lokal, pihak sponsor, dan pemerintah menjadi faktor pendorong terlaksananya program konsolidasi tanah. Penelitian lain dilakukan oleh Putra (2011) bertujuan untuk mengungkap pengaruh budaya lokal masyarakat dalam program konsolidasi tanah. Pada penelitian-penelitian yang telah dilakukan masih belum ditemukan penelitian yang membahas secara spesifik mengenai analisis stakeholder yang terlibat dalam program konsolidasi tanah sehingga penelitian ini dipandang relevan. Penelitian terdahulu dijadikan referensi yang membedakan penelitian ini dengan penelitian lain sebelumnya sehingga dapat terlihat keaslian penelitian.

\section{B. Metode}

Penelitian ini merupakan penelitian deskriptif kualitatif. Menurut Moleong (1993) metode kualitatif merupakan metode penelitian yang memuat data tertulis, lisan dan perilaku obyek yang diamati yang digambarkan secara deskriptif. Penelitian kualitatif mendeskripsikan hasil pengumpulan data yang valid dengan metode kualitatif melalui indepth interview, observasi, dan dokumentasi data sekunder. Kesimpulan diambil dengan tingkat kepercayaan yang tinggi dengan berpedoman kepada dependability, credibility, transferabillity, dan confirmability. Metode ini dipilih dengan harapan melalui penjabaran secara deskriptif dapat memberikan gambaran sedetail mungkin dalam penyajian hasil penelitian.

Penelitian ini mempunyai unit amatan berupa lokasi yang menjadi objek program konsolidasi tanah. Gambar 2 menunjukkan peta lokasi penelitian yang meliputi Desa Gadingsari Kecamatan Sanden Kabupaten Bantul Daerah Istimewa Yogyakarta. Desa dipilih karena merupakan salah satu lokasi yang dipandang berhasil dalam pelaksanaan program konsolidasi tanah. Batasan waktu yang digunakan yaitu pelaksanaan program konsolidasi tanah di Desa Gadingsari Tahun 2018. Unit analisa berupa identifikasi, kepentingan dan pengaruh stakeholder dalam program konsolidasi tanah. Teknik pengumpulan data dilakukan dengan observasi, wawancara, dan dokumentasi. Pemilihan narasumber menggunakan teknik purposive sampling yaitu teknik pemilihan narasumber yang dianggap paling mengetahui tentang apa yang diharapkan peneliti. Teknik ini didukung dengan teknik snowball sampling yaitu apabila narasumber yang ditemui belum memberikan data yang lengkap, maka akan menggunakan narasumber lain berdasarkan informasi dari narasumber sebelumnya. Sumber data yang digunakan meliputi data primer dan data sekunder. Data primer 
didapatkan secara langsung di lapangan melalui wawancara dan observasi, sedangkan data sekunder melalui dokumen/arsip, internet serta buku. Data dianalisis dengan mereduksi data, penyajian data dan mendapatkan kesimpulan.

Gambar 2. Peta Administrasi Desa Gadingsari

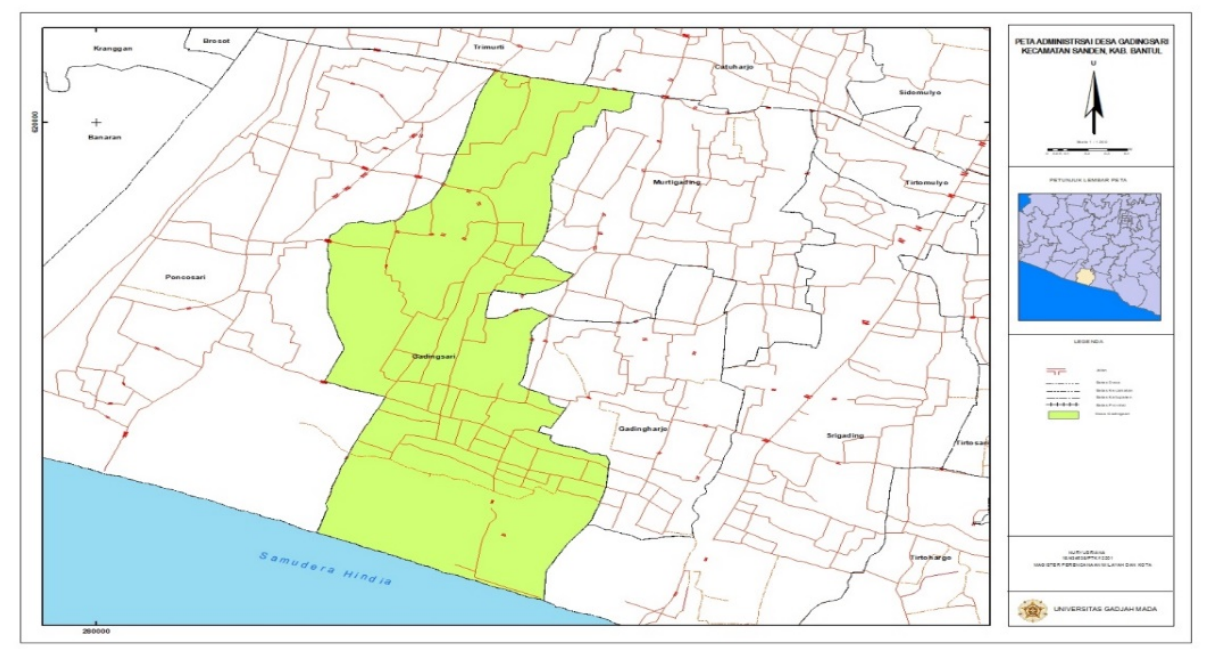

Sumber: ATR/BPN Provinsi DIY, 2018

\section{Pelaksanaan Program Konsolidasi Tanah di Desa Gadingsari}

Program konsolidasi tanah di Desa Gadingsari merupakan suatu program pemerintah di bidang pertanahan yang mengatur pemanfaatan dan penggunaan tanah pada masyarakat. Program ini dilaksanakan di daerah-daerah seluruh Indonesia. Program konsolidasi tanah ini merupakan salah satu program konsolidasi tanah dengan pembiayaan pemerintah. Desa Gadingsari terpilih menjadi lokasi objek konsolidasi tanah melalui suatu kajian yang dilaksanakan tim panitia serta masukan dari pemerintah daerah setempat. Berdasarkan Peraturan Daerah Nomor 04 Tahun 2011 tentang Rencana Tata Ruang Wilayah Kabupaten Bantul Tahun 2010-2030, Desa Gadingsari termasuk sebagai kawasan permukiman, dimana masyarakat secara swadaya telah membangun jalan pertolongan sebagai akses darurat menuju bidang tanah yang mereka tempati sebagai tempat tinggal. Program konsolidasi tanah dilaksanakan secara bertahap dengan sistem blok. Selengkapnya tabel konsolidasi tanah di Desa Gadingsari dapat dilihat pada tabel berikut.

Tabel 1. Rekapitulasi Pelaksanaan Program Konsolidasi Tanah di Desa Gadingsari

\begin{tabular}{|c|c|c|c|c|c|}
\hline No & Tahun & Lokasi & $\begin{array}{l}\text { Jumlah } \\
\text { Bidang }\end{array}$ & $\begin{array}{l}\text { Jumlah } \\
\text { Peserta }\end{array}$ & Luas (m2) \\
\hline 1. & 2009 & Wonorejo II & 300 & 267 & 136.795 \\
\hline 2. & 2010 & Wonorejo I & 200 & 156 & 86.546 \\
\hline 3. & 2011 & Wonorejo I & 223 & 200 & 97.460 \\
\hline 4. & 2013 & Bongos I dan Bongos II & 200 & 170 & 92.804 \\
\hline 5. & 2015 & $\begin{array}{l}\text { Bongos I, Demakan, } \\
\text { Nanggulan }\end{array}$ & 611 & 491 & 301.221 \\
\hline 6. & 2017 & $\begin{array}{l}\text { Nanggulan, Patihan, } \\
\text { Wonoroto }\end{array}$ & 200 & 172 & 111.467 \\
\hline 7. & 2018 & $\begin{array}{l}\text { Patihan, Wonoroto } \\
\text { Jumlah }\end{array}$ & $\begin{array}{l}300 \\
2.034 \\
\end{array}$ & $\begin{array}{l}251 \\
1.707\end{array}$ & $\begin{array}{l}342.500 \\
1.168 .793 \\
\end{array}$ \\
\hline
\end{tabular}

Sumber: ATR/BPN Provinsi DIY, 2018 
Berdasarkan data laporan konsolidasi tanah yang disusun ATR/BPN Kantor Wilayah Provinsi DIY pelaksanaan program konsolidasi tanah di Desa Gadingsari dilaksanakan pada tahun 2009 sampai dengan 2018 dengan pengecualian tahun 2012, 2014, dan 2016 dengan total 2.034 bidang seluas $1.168 .793 \mathrm{~m}^{2}$ dan diikuti 1.707 peserta. Masyarakat sangat antusias dalam mengikuti setiap tahapan dalam program konsolidasi tanah. Fenomena menarik dalam pelaksanaan program konsolidasi tanah adalah masyarakat dengan penuh kesadaran mengajukan lokasi lingkungan mereka untuk menjadi lokasi program konsolidasi tanah. Hal tersebut disampaikan kepada tokoh masyarakat maupun pihak BPN selaku pendamping kegiatan. Permohonan warga masyarakat inilah yang menyebabkan pelaksanaan program konsolidasi tanah dapat dilaksanakan secara berkesinambungan pada setiap bloknya.

Pelaksanaan program konsolidasi tanah di Desa Gadingsari terdiri atas beberapa tahapan yang mengacu pada petunjuk teknis pelaksanaan program konsolidasi tanah tahun 2018 yang diterbitkan oleh Direktorat Konsolidasi tanah, Deputi Pengadaan tanah untuk kepentingan umum, yaitu:

1. Pembentukan Tim Panitia

Pembentukan panitia konsolidasi tanah terdiri atas tim koordinasi dan tim pelaksana. Tim koordinasi terbentuk berdasarkan Surat Keputusan Bupati Bantul Nomor 295 Tahun 2018 tentang pembentukan tim koordinasi program konsolidasi tanah. Tim penyelenggara terbentuk berdasarkan Surat Keputusan Kepala Kantor Wilayah BPN DIY tentang penunjukan petugas pelaksana program konsolidasi tanah Desa Gadingsari. Anggota tim masing-masing berasal dari pemerintah daerah dan kementerian ATR/BPN.

2. Pemilihan Lokasi

Lokasi konsolidasi tanah dipilih berdasarkan berbagai pertimbangan, diantaranya kajian tata ruang, pemetaan sosial, analisa kawasan, kajian program sektor, kesiapan masyarakat, kondisi fisik lahan dan respons masyarakat. Penetapan lokasi program ini ditetapkan dengan Surat Keputusan Kepala Kantor Wilayah BPN Daerah Istimewa Yogyakarta tentang penunjukan lokasi program konsolidasi tanah di Desa Gadingsari.

3. Penyuluhan

Penyuluhan dilaksanakan dengan tujuan memberikan pemahaman terhadap masyarakat mengenai tujuan dan manfaat serta pelaksanaan program konsolidasi tanah. Penyuluhan dilaksanakan di tingkat pedukuhan dengan waktu penyuluhan berdasarkan kesepakatan yang telah disepakati oleh masyarakat.

4. Penjajakan Kesepakatan

Tahapan penjajakan kesepakatan merupakan musyawarah dengan masyarakat yang bertujuan mengetahui tingkat kesediaan masyarakat dalam mengikuti program konsolidasi tanah. Tahapan ini juga membahas mengenai sumbangan tanah untuk pembangunan (STUP).

5. Penetapan Lokasi

Penetapan lokasi program konsolidasi tanah ditetapkan melalui Surat Keputusan Bupati Bantul Nomor 330 Tahun 2018 tentang penetapan lokasi konsolidasi tanah di Desa 
Gadingsari. Surat keputusan ini memuat ditetapkannya Desa Gadingsari sebagai tanah objek konsolidasi tanah.

6. Identifikasi Subyek dan Obyek Konsolidasi Tanah

Tahapan ini berupa pengumpulan data subyek yang berupa fotokopi KTP dan KK serta data tanah sebagai obyek program konsolidasi tanah. Pada tahapan pengumpulan data yuridis ini, panitia dibantu oleh Pokmas yang telah terlebih dahulu dibentuk. Keberadaan Pokmas ini merupakan representasi peran serta aktif masyarakat dalam pelaksanaan program konsolidasi tanah.

7. Pengukuran dan Pemetaan Keliling

Pengukuran dan pemetaan keliling dilaksanakan dalam skala besar yang bertujuan untuk mengetahui letak lokasi, luas dan batas keliling obyek program konsolidasi tanah. Tahapan ini dilaksanakan oleh satgas fisik dari panitia pelaksanaan bersama dengan perangkat desa dan pemilik tanah.

8. Pengukuran dan Pemetaan Rincikan

Pengukuran dan pemetaan rincikan dilaksanakan dalam skala kecil dengan mengukur bidang-bidang tanah obyek konsolidasi tanah. Tahapan ini dilaksanakan oleh satgas fisik yang didampingi oleh perangkat desa dan pemilik tanah sebagai penunjuk batas.

9. Pengukuran dan Pemetaan Topografi

Tahapan ini dilaksanakan dengan tujuan mengetahui ketinggian dan sudut kemiringan lereng dan penggunaan tanah (present land use), sehingga dapat menjadi pertimbangan dalam penyusunan rencana blok dan desain konsolidasi tanah.

10. Penyusunan Rencana Blok Desain

Penyusunan rencana blok desain dilaksanakan secara musyawarah oleh masyarakat. Tahapan ini berupa penyampaian ide dalam penyusunan rencana desain bidang-bidang tanah secara fisik. Pada tahapan ini ditambahkan pula perencanaan bagi pembangunan fasilitas umum yang berupa jalan ataupun sarana dan prasarana lain yang diperlukan.

11. Penyusunan Desain Konsolidasi Tanah

Apabila tahapan rencana blok desain telah selesai dilaksanakan, maka tahapan selanjutnya yaitu menyusun desain dengan menentukan letak, bentuk dan luas bidang tanah pada lokasi program konsolidasi tanah. Penyusunan blok desain ini juga sangat dipengaruhi oleh bentuk, letak dan luas sumbangan tanah untuk pembangunan (STUP).

12. Musyawarah Rencana Penetapan Kapling Baru

Setelah desain konsolidasi tanah telah selesai disusun, maka desain tersebut dipaparkan dalam musyawarah, sehingga didapatkan masukan dari seluruh peserta konsolidasi tanah. Hasil yang telah disepakati dituangkan dalam berita acara musyawarah.

13. Pelepasan Hak Atas Tanah

Persyaratan legalitas dalam pemenuhan tanah sebagai obyek konsolidasi tanah adalah merupakan tanah negara, sehingga diperlukan pelepasan hak atas tanah yang telah dikuasai perseorangan/pribadi menjadi tanah yang dikuasai oleh negara atau tanah negara. Pelepasan hak ini dituangkan dalam surat pelepasan hak dan dilakukan di hadapan kepala kantor ATR/BPN Kabupaten Bantul. 
14. Penegasan Tanah Sebagai Obyek Konsolidasi

Penegasan tanah Desa Gadingsari sebagai tanah obyek konsolidasi tanah dituangkan dalam Surat Keputusan Kepala Kantor Wilayah ATR/BPN Provinsi Daerah Istimewa Yogyakarta tentang ditetapkannya tanah negara yang telah dilepaskan oleh masyarakat menjadi tanah objek konsolidasi tanah.

15. Realokasi/ Pemindahan Desain Konsolidasi Tanah ke Lapangan Pada tahapan ini dilakukan pekerjaan konstruksi yaitu memindahkan desain yang telah disusun ke lokasi program konsolidasi tanah. Bentuk bidang tanah, luas dan sarana dan prasarana yang akan dibangun mengacu pada desain yang telah ditetapkan berdasarkan hasil musyawarah yang telah dilakukan sebelumnya.

16. Pembentukan Badan Jalan dan Fasilitas Umum

Pembentukan badan jalan di lapangan dilaksanakan dengan pematokan akses jalan dan fasilitas umum berdasarkan desain yang telah disepakati sebelumnya. Pembangunan badan jalan masih berupa jalan tanah dan belum diperkeras, dan kemudian ditindaklanjuti oleh pemerintah desa untuk tahapan pengerasan jalan sehingga dapat dimanfaatkan secara optimal.

17. Penerbitan Surat Keputusan Pemberian Hak Atas Tanah

Surat keputusan pemberian hak atas tanah merupakan dasar dalam penerbitan sertipikat hasil konsolidasi tanah. Surat keputusan ini diterbitkan oleh ATR/BPN Kabupaten Bantul yang ditandatangani oleh kepala kantor pertanahan.

18. Penerbitan Sertipikat Tanah Hasil Konsolidasi

Penerbitan sertipikat hak milik hasil program konsolidasi tanah diterbitkan berdasarkan surat keputusan pemberian hak atas tanah. Dalam sertipikat ini, tanah yang digunakan untuk fasilitas umum telah dikeluarkan dari kepemilikan sertipikat sebelumnya, dan status tanah dikembalikan menjadi hak milik peserta program konsolidasi tanah. Sertipikat tanah menjadi bukti legal pemilik bidang tanah di lokasi konsolidasi tanah.

Gambar 3. Peta Desain Konsolidasi Tanah di Desa Gadingsari

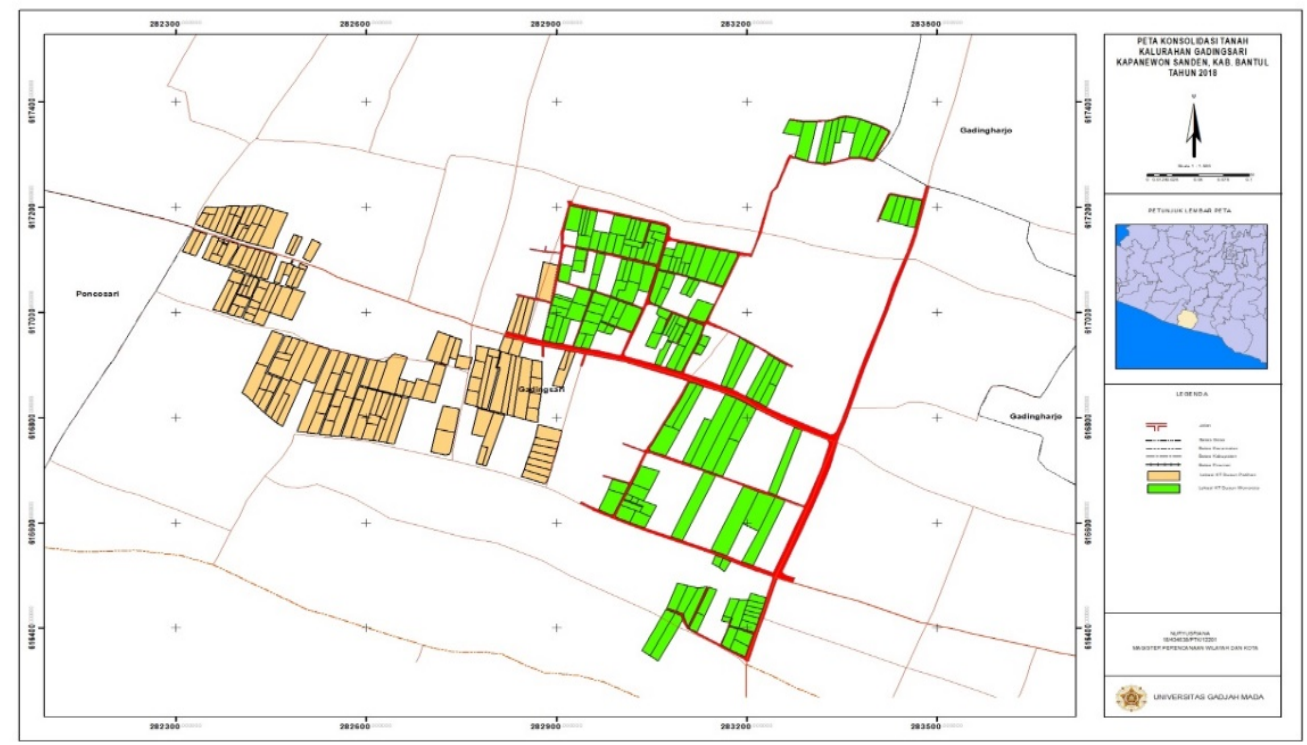

Sumber: ATR/BPN Provinsi DIY, 2018 
Gambar 3 menunjukkan peta desain konsolidasi tanah di Desa Gadingsari pada tahun 2018 yang meliputi dua dusun yaitu Dusun Patihan dan Dusun Wonoroto. Pelaksanaan program konsolidasi tanah di kedua dusun tersebut meliputi kawasan permukiman. Desain konsolidasi tanah tersebut disusun oleh masyarakat dengan pendampingan dari panitia konsolidasi tanah. Pada pelaksanaan program konsolidasi tanah tersebut dibangun fasilitas umum yang berupa jalan kampung yang menghubungkan bidang-bidang tanah yang belum mempunyai akses jalan.

\section{Identifikasi Stakeholder dalam Program Konsolidasi Tanah di Desa Gadingsari}

Program konsolidasi tanah merupakan program lintas sektor yang melibatkan banyak stakeholder dalam pelaksanaannya. Keterlibatan stakeholder dalam setiap tahapan konsolidasi tanah merupakan faktor kunci keberhasilan dalam program tersebut. Stakeholder yang terlibat dalam program konsolidasi tanah terdiri dari unsur pemerintah baik instansi vertikal maupun instansi di lingkup pemerintah Kabupaten Bantul. Stakeholder yang terlibat dalam program konsolidasi tanah Desa Gadingsari adalah sebagai berikut:

Tabel 2. Daftar Stakeholder Program Konsolidasi Tanah

\begin{tabular}{cl}
\hline No $\quad$ Klasifikasi & \multicolumn{1}{c}{ Stakeholder } \\
\hline 1. Pemerintah Pusat & a. ATR/BPN RI \\
& b. ATR/BPN Provinsi DIY \\
2. Pemerintah Daerah & $\begin{array}{l}\text { c. ATR/BPN Kab. Bantul } \\
\text { a. Bupati Bantul }\end{array}$ \\
& b. Bappeda Kabupaten Bantul \\
& c. Dinas Tata Ruang Kabupaten Bantul \\
& d. Dinas Pekerjaan Umum Kabupaten Bantul \\
& e. Dinas Pertanian Kabupaten Bantul \\
& f. Kecamatan Sanden \\
& g. Desa Gadingsari \\
3. Masyarakat & a. Masyarakat pemilik tanah \\
& b. Tokoh masyarakat \\
& c. Pokmas \\
\hline
\end{tabular}

Sumber: Hasil Penelitian, 2021

Stakeholder yang terlibat dalam pelaksanaan program konsolidasi tanah terdiri atas 3 (tiga) klasifikasi utama yaitu pemerintah pusat, pemerintah daerah dan masyarakat. Masyarakat pemilik tanah merupakan stakeholder primer yang terkena dampak langsung pada kegiatan konsolidasi tanah. Masyarakat terlibat penuh dalam setiap tahapan dan peran aktif masyarakat sangat terlihat pada pelaksanaan program konsolidasi tanah. Pada program konsolidasi tanah, instansi vertikal yaitu kementerian ATR/BPN baik ATR/BPN pusat, ATR/BPN Provinsi, Serta Kantor Pertanahan Kabupaten Bantul berperan sebagai stakeholder kunci yang mempunyai kewenangan legal dalam pengambilan keputusan. Bupati Kabupaten Bantul juga merupakan juga merupakan stakeholder kunci yang memiliki kewenangan legal dalam pengambilan keputusan yang meliputi penetapan lokasi program konsolidasi tanah. Stakeholder pendukung pada program konsolidasi tanah terdiri atas instansi daerah pada Pemerintah Kabupaten Bantul yang terdiri atas: Bappeda Kabupaten Bantul; Dinas Tata Ruang Kabupaten Bantul; Dinas Pekerjaan Umum Kabupaten Bantul; Dinas Pertanian Kabupaten Bantul; Pemerintah Kecamatan Sanden; Pemerintah Desa Gadingsari; Tokoh Masyarakat dan Pokmas. 


\section{E. Analisa Stakeholder dalam Program Konsolidasi Tanah di Desa Gadingsari}

Stakeholder dalam program konsolidasi tanah mempunyai kekuatan dan kepentingan yang berbeda-beda. Stakeholder yang terlibat dapat dipetakan sehingga terlihat kekuatan dan kepentingan masing-masing stakeholder. Masing-masing kekuatan dan kepentingan stakeholder pada program konsolidasi tanah di Desa Gadingsari adalah sebagai berikut.

Tabel 3. Kepentingan dan Kekuatan Stakeholder Program Konsolidasi Tanah

\begin{tabular}{|c|c|c|c|}
\hline No & Stakeholder & Kepentingan (Interest) & Kekuatan (Power) \\
\hline 1 & $\begin{array}{l}\text { Kementerian } \\
\text { ATR/BPN RI }\end{array}$ & $\begin{array}{l}\text { Terwujudnya program } \\
\text { reforma agraria }\end{array}$ & $\begin{array}{l}\text { karena pembuat kebijakan dan perencanaan } \\
\text { program secara nasional dan merupakan } \\
\text { pihak penyedia anggaran. }\end{array}$ \\
\hline 2 & $\begin{array}{l}\text { Kanwil BPN } \\
\text { Provinsi DIY }\end{array}$ & $\begin{array}{l}\text { Terwujudnya penataan, } \\
\text { pemanfaatan, penggunaan } \\
\text { dan kepemilikan tanah }\end{array}$ & $\begin{array}{l}\text { Kuat karena terlibat dalam semua tahapan } \\
\text { program konsolidasi tanah. }\end{array}$ \\
\hline 3 & $\begin{array}{l}\text { Kementerian } \\
\text { ATR/BPN } \\
\text { Kabupaten Bantul }\end{array}$ & $\begin{array}{l}\text { - Mewujudkan kepastian } \\
\text { hukum atas tanah } \\
\text { - Menjaga agar tidak } \\
\text { terjadi konflik } \\
\text { pertanahan }\end{array}$ & $\begin{array}{l}\text { Pengaruhnya kuat karena apabila tidak ada, } \\
\text { penerbitan sertipikat program KT tidak } \\
\text { selesai. }\end{array}$ \\
\hline 4 & Bupati Bantul & Kesejahteraan masyarakat & $\begin{array}{l}\text { Pengaruhnya kuat untuk penerbitan } \\
\text { penetapan lokasi konsolidasi tanah. }\end{array}$ \\
\hline 5. & $\begin{array}{l}\text { Bappeda Kab. } \\
\text { Bantul }\end{array}$ & $\begin{array}{l}\text { Penataan ruang sesuai } \\
\text { RTRW }\end{array}$ & $\begin{array}{l}\text { Memberikan masukan terkait penetapan } \\
\text { lokasi dan program yang terkait }\end{array}$ \\
\hline 6. & $\begin{array}{l}\text { Dinas Tata Ruang } \\
\text { Kab. Bantul }\end{array}$ & $\begin{array}{l}\text { Penataan ruang sesuai } \\
\text { RTRW }\end{array}$ & $\begin{array}{l}\text { Memberikan masukan terkait penetapan } \\
\text { lokasi dan program yang terkait }\end{array}$ \\
\hline 7. & $\begin{array}{l}\text { Dinas Pekerjaan } \\
\text { Umum }\end{array}$ & $\begin{array}{l}\text { Terbangunnya fasilitas } \\
\text { umum/ aksesibilitas }\end{array}$ & $\begin{array}{l}\text { Menindaklanjuti hasil program konsolidasi } \\
\text { tanah }\end{array}$ \\
\hline 8. & $\begin{array}{l}\text { Dinas Pertanian } \\
\text { Kab. Bantul }\end{array}$ & $\begin{array}{l}\text { Tertatanya lahan } \\
\text { pertanian }\end{array}$ & $\begin{array}{l}\text { Memberikan masukan terkait penetapan } \\
\text { lokasi dan program terkait }\end{array}$ \\
\hline 9 & $\begin{array}{l}\text { Pemerintah Kec. } \\
\text { Sanden }\end{array}$ & Pelaksanaan pembangunan & $\begin{array}{l}\text { Berpengaruh dalam koordinasi dan } \\
\text { sosialisasi }\end{array}$ \\
\hline 10 & $\begin{array}{l}\text { Pemerintah Desa } \\
\text { Gadingsari }\end{array}$ & $\begin{array}{l}\text { Penataan lingkungan dan } \\
\text { pembangunan aksesibilitas } \\
\text { (jalan) }\end{array}$ & $\begin{array}{l}\text { Pengaruhnya kuat, semua tahapan. } \\
\text { Berperan dalam pelepasan hak tanah }\end{array}$ \\
\hline 11 & $\begin{array}{l}\text { Masyarakat } \\
\text { Pemilik Tanah }\end{array}$ & $\begin{array}{l}\text { - Membangun aksesibilitas } \\
\text { - Mempunyai tanda milik } \\
\text { yang sah secara hukum } \\
\text { atas kepemilikan tanah } \\
\text { yaitu sertipikat }\end{array}$ & $\begin{array}{l}\text { Pengaruhnya sangat kuat karena lahan objek } \\
\text { konsolidasi tanah dimiliki oleh masyarakat }\end{array}$ \\
\hline 12 & Tokoh Masyarakat & $\begin{array}{l}\text { Program konsolidasi tanah } \\
\text { berjalan dengan lancar }\end{array}$ & $\begin{array}{l}\text { Pengaruhnya tidak kuat karena program } \\
\text { konsolidasi tanah dapat terlaksana tanpa } \\
\text { perantara atau peranan tokoh masyarakat, } \\
\text { tetapi jika karakter tokoh masyarakat kuat } \\
\text { akan mempunyai pengaruh yang cukup } \\
\text { tinggi untuk keberhasilan program. }\end{array}$ \\
\hline 13 & Pokmas & $\begin{array}{l}\text { Membantu melaksanakan } \\
\text { pengumpulan data yuridis }\end{array}$ & $\begin{array}{l}\text { Pengaruhnya tidak kuat karena bersifat } \\
\text { membantu pelaksanaan kegiatan. Pokmas } \\
\text { membuat puldadis lebih cepat dan efektif. }\end{array}$ \\
\hline
\end{tabular}

Sumber: Hasil Penelitian, 2021 
Berdasarkan rekapitulasi kepentingan, dan kekuatan stakeholder dalam pelaksanaan program konsolidasi tanah, maka dapat dipetakan tingkat pengaruh dan kepentingan masing-masing stakeholder dalam program konsolidasi tanah di Desa Gadingsari, sebagai berikut.

Gambar 4. Pemetaan Stakeholder dalam Pelaksanaan Program Konsolidasi Tanah

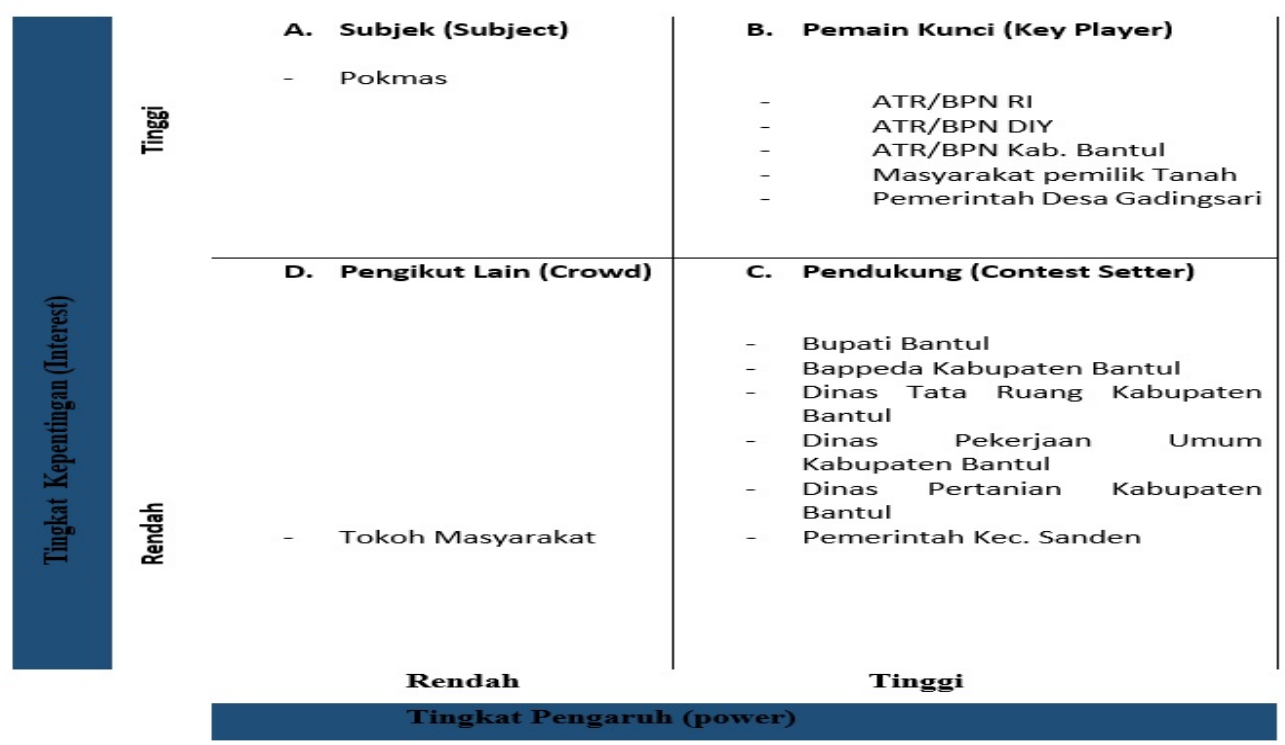

Sumber: Hasil Penelitian, 2021

Gambar 4 menunjukkan bahwa pada pelaksanaan program konsolidasi tanah dapat dipetakan menjadi 4 kuadran. Kuadran pertama (A) menunjukkan subject yang merupakan stakeholder yang mempunyai tingkat kepentingan tinggi tetapi memiliki kemampuan (power) yang rendah. Pokmas dibentuk dalam lingkup RT dan membantu tugas satgas yuridis dalam pengumpulan data. Pokmas merupakan stakeholder yang potensial dan perlu diberdayakan serta dilibatkan lebih jauh lagi dalam pelaksanaan program konsolidasi tanah.

Kuadran kedua menunjukkan key player atau pemain kunci dalam program konsolidasi tanah. Stakeholder yang terlibat pada kuadran kedua merupakan stakeholder yang aktif dan sebagai penggerak utama dalam program ini. Stakeholder yang masuk dalam kuadran kedua ini yaitu ATR/BPN baik di tingkat pusat, provinsi maupun kabupaten, pemerintah desa dan masyarakat pemilik tanah. Masing-masing stakeholder mempunyai kepentingan dan pengaruh yang tinggi dalam program konsolidasi tanah. Program konsolidasi tanah merupakan tupoksi utama bagi ATR/BPN yang juga adalah program nasional di bidang pertanahan dimana tata cara, penganggaran ataupun persetujuannya tergantung kepada pemerintah pusat. ATR/BPN provinsi, ATR/BPN Kabupaten, berperan kuat dalam tahapan pelaksanaan program konsolidasi tanah, yang berperan sebagai penggerak utama dalam pelaksanaan program konsolidasi tanah. Pada kuadran ini juga terdapat stakeholder masyarakat pemilik tanah dan pemerintah desa. Masyarakat pemilik tanah mempunyai kepentingan tinggi terkait status pemilikan, penguasaan, penggunaan dan pemanfaatan tanah yang mereka miliki. Masyarakat pemilik tanah mempunyai kepentingan yang tinggi untuk menata tanah yang mereka tempati sehingga teratur, mempunyai aksesibilitas yang baik dan berkekuatan hukum tetap atas hak kepemilikannya. Sedangkan desa mempunyai kepentingan tinggi terkait penataan tanah di lingkup desa agar desa menjadi lebih rapi, sehat dan teratur. Terbangunnya aksesibilitas yang baik juga bermanfaat untuk kedua stakeholder ini. 
Pada kuadran ke tiga terdapat contest setter yang merupakan stakeholder pendukung dalam pelaksanaan program konsolidasi tanah. Stakeholder pendukung ini mempunyai pengaruh yang tinggi dengan kepentingan yang rendah. Pemerintah Kabupaten Bantul mempunyai pengaruh tinggi terkait dengan kewenangannya dalam penetapan lokasi program konsolidasi tanah. Pemerintah kecamatan mempunyai wewenang untuk tidak memberikan izin terhadap program kegiatan konsolidasi tanah yang berlokasi dalam wilayah administrasinya.

Kuadran ke empat terdapat stakeholder yang berperan sebagai crowd yang mempunyai kepentingan dan kekuatan rendah pada pelaksanaan konsolidasi tanah. stakeholder yang terdapat dalam kuadran ini yaitu tokoh masyarakat. Keberadaan stakeholder ini tidak memberikan pengaruh yang signifikan, tetapi keberadaan tokoh masyarakat akan memperkuat keberhasilan pelaksanaan program konsolidasi tanah.

Analisa peran stakeholder menemukan beberapa tipologi peran dalam pelaksanaan program konsolidais tanah, yaitu:

1. Pembuat Kebijakan

Peran stakeholder sebagai pembuat kebijakan berupa menyusun peraturan terkait program konsolidasi tanah; menetapkan surat keputusan susunan kepanitiaan Program konsolidasi tanah; mengeluarkan surat pemberian hak atas tanah; menetapkan surat keputusan penetapan lokasi konsolidasi tanah, mengeluarkan arahan pelaksanaan pekerjaan konstruksi; mengeluarkan peraturan pembangunan fasilitas umum dan mengeluarkan resolusi penanganan konflik pada permasalahan/sengketa.

2. Koordinator

Peran stakeholder sebagai koordinator meliputi mengkoordinasikan kegiatan-kegiatan dalam program konsolidasi tanah; mengkoordinasikan rapat dan pertemuan pada pelaksanaan konsolidasi tanah; koordinasi dalam kegiatan penyuluhan; koordinator pada pengumpulan data fisik dan yuridis; koordinator dalam kegiatan konstruksi dalam pelaksanaan program konsolidasi tanah.

3. Fasilitator

Peran stakeholder sebagai fasilitator meliputi penyediaan dana; menyediakan sarana dan prasarana operasional; menyediakan peralatan pengumpulan data fisik dan yuridis; melakukan pemberdayaan masyarakat dalam pelaksanaan program konsolidasi tanah; menyediakan lahan (STUP).

4. Pelaksana

Peran stakeholder sebagai pelaksana meliputi melaksanakan kegiatan pemilihan lokasi; melaksanakan kegiatan peninjauan lokasi; melaksanakan rapat koordinasi; melaksanakan kegiatan sosialisasi; melaksanakan pengumpulan data fisik dan yuridis; melaksanakan pembuatan desain kapling; melaksanakan kegiatan konstruksi.

5. Perencana

Peran stakeholder sebagai perencana meliputi menyusun dokumen tata cara kerja program konsolidasi tanah; menyusun perencanaan lokasi; menyusun rencana kerja; menyusun rencana anggaran; menyusun jadwal kegiatan. 


\section{Mediator}

Peran stakeholder sebagai mediator meliputi melakukan mediasi dalam permasalahan program konsolidasi tanah; dan memberikan resolusi konflik bagi pihak-pihak yang bersengketa.

Berdasarkan tabel 4 dapat diketahui bahwa: (1) pemerintah pusat dan daerah berperan sebagai pembuat kebijakan; (2) pemerintah pusat dan pemerintah daerah serta masyarakat pemilik tanah berperan sebagai perencana; (3) peran sebagai fasilitator dijalankan semua stakeholder; (4) peran koordinator dilaksanakan oleh beberapa stakeholder yaitu: ATR/BPN Provinsi DIY; ATR/BPN Kab. Bantul; Pemerintah Desa Gadingsari; Tokoh Masyarakat dan Pokmas; (5) peran pelaksana dilaksanakan oleh semua stakeholder; (6) peran sebagai mediator dilaksanakan oleh ATR/BPN Provinsi DIY; ATR/BPN Kab. Bantul; Pemerintah Desa Gadingsari; Tokoh masyarakat

Tabel 4. Kedudukan Tipologi Peran Stakeholder dalam Program Konsolidasi Tanah

\begin{tabular}{|c|c|c|c|c|c|c|c|}
\hline No & Stakeholder & $\begin{array}{l}\text { Pembuat } \\
\text { Kebijakan }\end{array}$ & Perencana & Fasilitator & Koordinator & Pelaksana & Mediator \\
\hline 1. & $\begin{array}{l}\text { ATR/BPN } \\
\mathrm{RI}\end{array}$ & $\mathrm{V}$ & V & V & & & \\
\hline 2. & ATR/BPN Prov. DIY & $\mathrm{V}$ & V & V & $\mathrm{V}$ & $\mathrm{V}$ & $\mathrm{V}$ \\
\hline 3. & $\begin{array}{l}\text { ATR/BPN } \\
\text { Kab. Bantul }\end{array}$ & V & V & V & V & V & V \\
\hline $\begin{array}{l}4 . \\
5 .\end{array}$ & $\begin{array}{l}\text { Bupati Kab. Bantul } \\
\text { Bappeda }\end{array}$ & V & $\begin{array}{l}\mathrm{V} \\
\mathrm{V}\end{array}$ & V & & & \\
\hline 6. & Dinas Tata Ruang & & V & & & & \\
\hline 7. & Dinas PU & & V & & & & \\
\hline 8. & Dinas Pertanian & & V & & & & \\
\hline 9. & $\begin{array}{l}\text { Pemerintah Kec. } \\
\text { Sanden }\end{array}$ & & V & V & & & \\
\hline 10. & $\begin{array}{l}\text { Pemerintah Desa } \\
\text { Gadingsari }\end{array}$ & & V & V & V & V & V \\
\hline 11. & $\begin{array}{l}\text { Masyarakat pemilik } \\
\text { tanah }\end{array}$ & & V & V & V & V & \\
\hline 12. & Tokoh Masyarakat & & & V & & & V \\
\hline 13. & Pokmas & & & V & V & V & \\
\hline
\end{tabular}

Sumber: Hasil Penelitian, 2021

Temuan penelitian sejalan dengan teori yang dikemukakan oleh Nugraha (2014) bahwa peran stakeholder terdiri atas (1) Policy Creator atau pembuat kebijakan; (2) Koordinator; (3) Fasilitator; (4) Implementer atau pelaksana; (5) Akselerator. Adapun peran akselerator masih belum dapat ditemukan secara jelas dalam penelitian ini, hal tersebut dikarenakan ATR/BPN RI berperan sebagai pembuat kebijakan, perencana dan fasilitator sehingga peran sebagai akselerator belum terlihat pada program konsolidasi ini. Temuan penelitian turut memberikan kontribusi teoritis pada penelitian yang membahas tentang peran stakeholder. Temuan baru yang didapatkan dari penelitian ini adalah peran stakeholder sebagai perencana (planner) dan peran stakeholder sebagai mediator. 


\section{F. Kesimpulan}

Program konsolidasi tanah Desa Gadingsari merupakan program pemerintah di bidang pertanahan yang dilaksanakan sebagai upaya penataan kembali penguasaan, kepemilikan, penggunaan tanah, dan pengadaan tanah untuk kepentingan pembangunan dalam rangka meningkatkan kualitas lingkungan dan pemeliharaan sumber daya dengan melibatkan peran aktif masyarakat. Program konsolidasi tanah merupakan program lintas sektor yang melibatkan beberapa stakeholders didalamnya, yaitu ATR/ BPN Republik Indonesia; ATR/BPN Provinsi Daerah Istimewa Yogyakarta; ATR/BPN Kabupaten Bantul; Bupati Bantul, Bappeda Kabupaten Bantul; Dinas Tata Ruang Kabupaten Bantul; Dinas Pekerjaan Umum Kabupaten Bantul; Dinas Pertanian Kabupaten Bantul; Pemerintah Kecamatan Sanden; Pemerintah Desa Gadingsari; Masyarakat Pemilik Tanah; Tokoh Masyarakat dan Pokmas.

Adapun pada pemetaan stakeholder berdasarkan kepentingan dan pengaruhnya diketahui bahwa terdapat 4 (empat) kuadran yang terdiri atas: (1) subjek yang terdiri atas pokmas; (2) pemain kunci yang terdiri atas: ATR/ BPN Republik Indonesia; ATR/BPN Provinsi Daerah Istimewa Yogyakarta; ATR/BPN Kabupaten Bantul; masyarakat pemilik tanah; dan Pemerintah Desa Gadingsari; (3) Pendukung yang terdiri atas Bupati Bantul, Bappeda Kabupaten Bantul; Dinas Tata Ruang Kabupaten Bantul; Dinas Pekerjaan Umum Kabupaten Bantul; Dinas Pertanian Kabupaten Bantul; Pemerintah Kecamatan Sanden; (4) Pengikut lain yaitu tokoh masyarakat.

Peran stakeholder dalam program konsolidasi tanah yaitu (1) Policy Creator atau pembuat kebijakan; (2) Koordinator; (3) Fasilitator; (4) Implementer atau pelaksana; (5) Perencana; (6) Mediator.

\section{Daftar Pustaka}

Cohen, J. M., \& Uphoff, N. (1977). Rural development participation: Concepts and measures for project design. Implementation and Evaluation. New York (US): Cornell University.

Freeman, R. (1984). Strategic Management A Stakeholder Approach. London: Pitman Publishing Inc. Imaduddin, Z. (2019). Penataan Kawasan Rawan Bencana III Gunung Api Merapi dengan Konsolidasi Tanah di Desa Umbulharjo Kecamatan Cangkringan Kabupaten Sleman. Yogyakarta: MPWK UGM.

Jayadinata, J. (1999). Tata Guna Tanah Dalam Perencanaan Perkotaan dan Wilayah. Bandung: ITB Bandung.

Moeleong, L. (1993). Metodologi Penelitian Kualitatif. Bandung: Remaja Roda Karya.

Nugroho, H. C., Zauhar, S., \& Suryadi, S. (2014). Koordinasi Pelaksanaan Program Pengembangan Kawasan Agropolitan di Kabupaten Nganjuk. Indonesian Journal of Environment and Sustainable Development, 5(1), 12-22.

Prabowo, H. (2015). Konsolidasi Tanah Gadingsari Sebagai Alternatif Model Pertanahan Partisipasif. Yogyakarta: BPN.

Putera, N. (2011). Peran Budaya Lokal Masyarakat Dalam Pelaksanaan Konsolidasi Tanah di Kawasan Bukit Jati Kabupaten Gianyar Bali. Yogyakarta: MPKD UGM. 
Sinta, H. M. (2019). Konsolidasi Tanah sebagai Instrumen dalam Pengembangan Ibukota Kabupaten Limapuluh kota. Yogyakarta: MPWK UGM.

Sitorus, O. (1996). Konsolidasi Tanah Perkotaan Suatu Tinjauan Hukum. Yogyakarta: Mitra Kebijakan Tanah Indonesia.

Soesilo. (2000). Reformasi Pembangunan dengan Langkah - Langkah Manajemen Strategis. Jakarta: UI.

Suyanto, D. (2013). Konsolidasi Tanah Swadaya di Desa Darmasaba Kecamatan Abiansemal Kabupaten Badung Provinsi Bali. Yogyakarta: MPKD UGM.

Wakka, A. K. (2014). Analisis Stakeholders Pengelolaan Kawasan Hutan dengan Tujuan Khusus (KHDTK) Mengkendek, Kabupaten Tana Toraja, Provinsi Sulawesi Selatan. Jurnal Penelitian Kehutanan Wallacea, 3(1), 47-55. 